\title{
ARBORIZAÇÃO DE RUAS E ACESSIBILIDADE NO BAIRRO CENTRO DE CURITIBA-PR
}

Everaldo Marques de Lima Neto ${ }^{1}$, Michella Yamamura Bardelli-da-Silva ${ }^{2}$, Ana Raquel da Silva ${ }^{3}$, Daniela Biondi ${ }^{4}$

(recebido em 07.04.2010 e aceito para publicação em 15.12.2010)

\section{RESUMO}

A avaliação da arborização de ruas tem se intensificado nos últimos anos, visto a importância na aplicação de políticas de conservação em ambientes urbanos, porém pouco se sabe a respeito da acessibilidade do público nas ruas. Nesse sentido o objetivo deste trabalho é analisar a arborização viária do centro de Curitiba-PR focando a questão da acessibilidade nas ruas. A metodologia consistiu na identificação e localização das espécies arbóreas, avaliando as características das árvores e do ambiente. No censo da arborização foram encontrados 1537 indivíduos, sendo que a espécie mais freqüente foi Ligustrum lucidum, uma das que apresentou problema relacionado com a raiz, favorecendo a quebra de calçadas. Hibiscus rosa-sinensis, de pequeno porte, apresentou maior freqüência de tortuosidade. Eugenia uniflora apresentou altura de bifurcação abaixo de 1,80 m em 100\% dos indivíduos presentes no bairro. Quanto ao tipo de calçada, o tipo paralelepípedo, que pode dificultar o acesso de pessoas, correspondeu a 70,33\%. A área para o passeio nas calçadas atendeu o mínimo exigido (1,20 m) correspondendo a 95,25\%. Para um melhor planejamento é necessário que seja feita uma seleção de espécies que apresentem características de raiz pivotante e condições de manejo compatíveis ao acesso do público às ruas.

Palavras-chave: arborização urbana, acessibilidade, inventário florestal, conservação.

\footnotetext{
1 Engenheiro Florestal, Mestrando em Engenharia Florestal - UFPR, Curitiba/PR. everaldo.limaneto@gmail.com

2 Engenheira Florestal, Doutoranda em Engenharia Florestal - UFPR, Curitiba/PR. myamamura@uol.com.br

${ }_{3}$ Tecnóloga Ambiental, Mestranda em Engenharia Florestal - UFPR, Curitiba/PR. anaraqueldasilva@gmail.com

4 Engenheira Florestal, Dr $\stackrel{\text { a }}{4}$ Professora Associada Depto. Ciências Florestais, UFPR, Bolsista Produtividade em Pesquisa - CNPq, Curitiba/PR. dbiondi@ufpr.br
} 


\section{STREETS TREE PLANTING AND ACCESSIBILITY IN CURITIBA'S DOWNTOWN NEIGHBORHOOD}

\section{ABSTRACT}

The evaluation of street tree planting has been intensified in recent years, in regard of the importance given to the implementation of conservation policies in urban environments, but little is known about the public accessibility in the streets. The aim of this paper is to analyze the streets tree planting in Curitiba's downtown neighborhood focusing on the issue of accessibility in the streets. The methodology involved the identification and location of tree species, evaluating the features of the trees and environment. In the census of trees 1,537 subjects were identified, and the most frequent species was Ligustrum lucidum, one of the species where root-related problems were observed, favoring the damage to sidewalks. Hibiscus rosa-sinensis, a small sized species, had a higher frequency of tortuosity. Eugenia uniflora presented fork height below $1.80 \mathrm{~m}$ in $100 \%$ of the subjects found in the neighborhood. Regarding the type of sidewalk, the parallelepiped, which can hinder the access to people, achieved $70.33 \%$. The walking area met the minimum required $(1.20 \mathrm{~m})$ in $95.25 \%$ of the sidewalks. For a better planning there is a need to provide a selection of species with the feature of pivoting roots and management conditions compatible with the public access to the streets.

Keywords: urban tree planting, accessibility, forest inventory, conservation. 


\section{INTRODUÇÃO}

O crescimento das cidades e a falta de planejamento ocasionam vários infortúnios à arborização urbana, uma vez que, ocorre a supressão da vegetação para dar lugar aos equipamentos urbanos.

A acessibilidade nos centros urbanos é um ponto chave para o planejamento das cidades de modo a conciliar os equipamentos urbanos - postes, árvores, canteiros, lixeiras, letreiros, placas de sinalização - permitindo assim o fluxo de pedestres. Para tal planejamento a aplicação de políticas de conservação da natureza, com ênfase na gestão da arborização de ruas é um parâmetro de avaliação e efetivação dos acessos sem a eliminação das árvores.

A arborização urbana confere inúmeras funções, entre elas, a melhoria no equilíbrio edáfico e microclimático através do sombreamento e da transpiração vegetal, redução na velocidade do vento e poluição sonora, contribuição para conservação e manutenção da avifauna e ecossistemas naturais, e, sobretudo, na qualidade de vida da população. Desse modo é necessária a implantação e conservação dos elementos arbóreos nas cidades.

Com relação ao fluxo de pedestres é necessário atender as necessidades das pessoas com mobilidade reduzida, que em geral, são mais prejudicadas no que se refere ao acesso aos serviços nas cidades. As estimativas da Organização das Nações Unidas (ONU) citado em Brasil Acessível (2005) mostram que aproximadamente 10\% da população dos países em desenvolvimento são constituídas por pessoas com deficiência permanente ou temporária. Dados do Instituto Brasileiro de Geografia e Estatística indicaram que 14,5\% da população brasileira são portadoras de deficiência (IBGE, 2000).

Nas ruas, as calçadas são as áreas de domínio público que permitem a locomoção propiciando a acessibilidade a diversos locais nas cidades. Segundo Pereira (2006), as calçadas das vias públicas não foram dimensionadas para comportar arborização, uma vez que o traçado urbano sempre priorizou o incremento de áreas para veículos, em detrimento dos pedestres.

Nesse sentido elementos da urbanização, tais como: fiação, outdoors, placas de sinalização, rede de esgoto e cabos subterrâneos alteram e/ou impedem o desenvolvimento das árvores no ambiente urbano. A arborização viária é de interesse coletivo, mas que, quando em local ou com árvores de características indesejáveis, atrapalham o pedestre, prejudicando o percurso seguro.

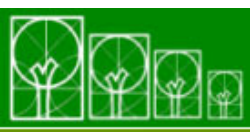

$\mathbf{S} \cdot \mathbf{B} \cdot \mathbf{A} \cdot \mathbf{U}$ Soc. Bras. de Arborização Urbana 
Vários conflitos são gerados quando as espécies apresentam características não desejáveis e/ou apresentam comportamento diferente do ambiente natural, como alterações no porte, árvores com raízes que se desenvolvem acima do solo, provocando quebra das calçadas, impedindo o trânsito livre de pedestres em especial deficientes e de mobilidade reduzida.

De acordo com Guia dos Direitos das Pessoas com Deficiência (2007), toda pessoa com deficiência ou com mobilidade reduzida, tem os seus direitos assegurados pela "Declaração Universal dos Direitos Humanos”, Carta de 1988, Organização das Nações Unidas, Organização Mundial da Saúde e demais legislações federais, estaduais e municipais. Leis estas, que objetivam a concretização efetiva de uma cidade humanizada e com acessibilidade a todos os direitos que the são garantidos, como também o acesso dessas pessoas com deficiências a locais públicos e privados, garantindo-lhes sua inclusão social.

Além disso, o fato das construções de calçadas ficarem, por determinação legal, a cargo do morador, sem um processo de fiscalização, por parte do poder público, agrava ainda mais a situação, fazendo com que não sejam respeitadas, por exemplo, as normas de dimensões corretas de acessibilidade ao pedestre, de abertura de canteiros para ajardinamento e de escolha de espécies (PEREIRA, 2006).

Os planos diretores e legislação das cidades determinam calçadas de diferentes estruturas, ou seja, a construção das calçadas no país não segue um padrão, dependendo da política, história e economia local.

Por outro lado o Conselho Regional de Engenharia, Arquitetura e Agronomia (CREA) do Paraná, elaborou um roteiro de acessibilidade que foi desenvolvido dentro de parâmetros técnicos levando em consideração a construção, instalação e adaptação das edificações, mobiliários e equipamentos urbanos para dar suporte à qualquer pessoa a utilização de maneira autônoma e segura do ambiente (CREA-PR, 2008).

Existem programas com o objetivo de melhorar a paisagem urbana e dar condições ao desenvolvimento da acessibilidade, são eles: Projeto Calçada Cidadã (Vitória/ES), Calçada Cidadã: Normas para Construção, Reforma e Conservação de Calçadas (Guarapari/ES), Calçada para Todos (Londrina/PR) e Programa Passeio Livre (São Paulo/SP), entre outros (VITÓRIA, 2002; GUARAPARI, 2009; LONDRINA, 2004; SÃO PAULO, 2005).

Sob a égide da conservação da natureza em áreas urbanas e também como forma de ampliar a construção de espaços menos hostis nas cidades, tem-se a necessidade de

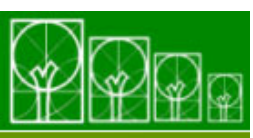

$\mathbf{S} \cdot \mathbf{B} \cdot \mathbf{A} \cdot \mathbf{U}$ Soc. Bras. de Arborização Urbana 
estudar as árvores de ruas e sua compatibilidade com as calçadas para possibilitar maior qualidade de vida e estender as oportunidades de acesso a todos os cidadãos.

Nesse sentido o objetivo deste trabalho é analisar a arborização viária do centro de Curitiba-PR focando a questão da acessibilidade nas ruas com intuito de proporcionar melhor planejamento da área de maior fluxo de indivíduos e permitir o trânsito de pedestres com maior flexibilidade no bairro, garantindo a permanência e implantação da arborização.

\section{MATERIAL E MÉTODOS}

\section{Caracterização da área de estudo}

O Município de Curitiba localiza-se na Região Sul do Brasil, situado na porção leste do Estado do Paraná ou primeiro planalto (MAACK, 1981). Possui altitude média de 934,6 m e relevo caracterizado por formas suave-onduladas (PMC, 2010).

Segundo a classificação de Köppen, a cidade possui clima do tipo Cfb e média anual de temperatura de $17^{\circ} \mathrm{C}$. A vegetação de ocorrência natural é Floresta Ombrófila Mista e Estepe Gramíneo-Lenhosa (RODERJAN et al., 2002).

$\mathrm{O}$ estudo foi realizado no centro (Figura 01), pertencente à sede administrativa Matriz. Este representa 0,76\% do território municipal, segundo dados do Censo IBGE 2000, concentra-se 2,06\% da população (32.623 habitantes) e densidade de 98,95hab/ $\mathrm{m}^{2}$, além de $3,7 \%$ dos domicílios. De acordo com o mesmo censo, 12,96\% da população possuem algum tipo de deficiência permanente (IPPUC, 2009). 


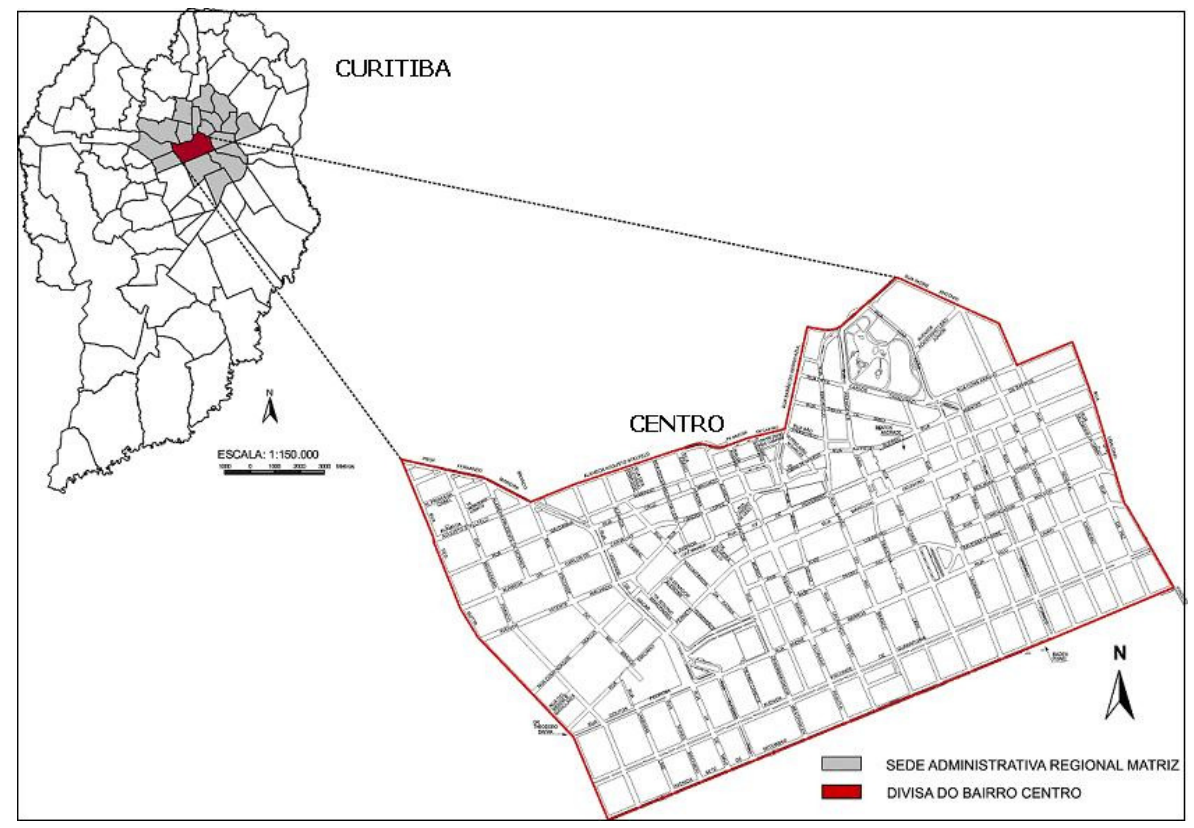

FIGURA 1: Município de Curitiba, em primeiro plano destaque para o centro, e em segundo plano destaque Sede Administrativa Matriz. Fonte: modificado de IPPUC (2005).

FIGURE 1: Curitiba city, the foreground highlighting downtown and the background highlighting the Administrative Headquarters Matrix. Source: adapted from IPPUC (2005).

A escolha do local de pesquisa teve como base a importância dos acessos aos pedestres, nos centros das grandes cidades.

\section{Procedimentos Metodológicos}

Foi realizado um inventário censo na arborização viária da área estudada utilizandose o mapa do centro, desenvolvido pelo IPPUC (2005). Para a coleta de dados foi estabelecido que as árvores a serem amostradas tivessem CAP (Circunferência à altura do peito) igual ou superior a $15 \mathrm{~cm}$. Os itens avaliados no levantamento estão descritos a seguir:

- A) características das árvores:

- identificação da árvore: Localização e nome vulgar da espécie arbórea avaliada; condição de raiz (opções $\mathrm{R} 1, \mathrm{R} 2$ e $\mathrm{R} 3$, respectivamente raiz superficial na calçada, superficial no canteiro e subterrânea); tortuosidade (opções sim e não e direcionamento quanto aos pontos cardeais); CAP transformados em DAP; altura de bifurcação (se maior que 1,80 é bifurcação positiva se menor, negativa); com fita métrica ou trena; 
- B) características do ambiente:

- tipo de calçada, opções: A - bloco de concreto pré-moldado, B - Concreto Betuminoso Usinado a Quente (CBUQ) com fiada de paralelepípedo intertravado, C - placa de concreto pré-moldado, $40 \mathrm{~cm} \times 40 \mathrm{~cm}$ ou $45 \mathrm{~cm} \times 45 \mathrm{~cm}$ com rejunte nivelado, D - Petit Pavet, E - paralelepípedo, F - Mista (combinação de dois tipos de calçamento) e G - Cimento; medidas da calçada (largura do canteiro, largura do canteiro à construção e largura do canteiro ao meio fio).

Foram realizadas quatro saídas a campo, e após cada saída os dados eram tabulados no programa Microsoft Excel e agrupados para cálculos, os resultados foram apresentados em lista de freqüência e percentagens. 


\section{RESULTADOS E DISCUSSÃO}

No levantamento foram analisados 1537 indivíduos sendo que 2,27\% destes não foram identificadas. Na Tabela 01, são apresentadas as espécies com mais de 10 indivíduos encontrados na arborização de ruas do centro de Curitiba-PR com informações do nome popular, nome científico, família, DAP e freqüência relativa.

TABELA 1 - Espécies arbóreas identificadas que apresentaram mais de 10 indivíduos no centro de Curitiba - PR.

TABLE 1 - Tree species identified with more than 10 individuals in Curitiba's downtown.

\begin{tabular}{|c|c|c|c|c|}
\hline $\begin{array}{l}\text { Nome } \\
\text { Popular }\end{array}$ & Nome Científico & Família & $\begin{array}{c}\text { DAP } \\
\text { Médio (m) }\end{array}$ & $\begin{array}{l}\text { Freqüência } \\
\text { Relativa (\%) }\end{array}$ \\
\hline Ligustro & Ligustrum lucidum Aiton & Oleaceae & 0,35 & 21,30 \\
\hline Extremosa & Lagerstroemia indica L. & Lythraceae & 0,15 & 16,71 \\
\hline Cinamomo & Melia azedarach Blanco & Meliaceae & 0,32 & 11,32 \\
\hline Dedaleiro & $\begin{array}{c}\text { Lafoensia pacari Saint- } \\
\text { Hilaire }\end{array}$ & Lythraceae & 0,13 & 9,25 \\
\hline Ipê-roxo & $\begin{array}{c}\text { Tabebuia heptaphylla (Vell.) } \\
\text { Toledo }\end{array}$ & Bignoniaceae & 0,35 & 6,59 \\
\hline Tipuana & $\begin{array}{c}\text { Tipuana tipu (Benth.) O. } \\
\text { Kuntze }\end{array}$ & Fabaceae & 0,51 & 6,59 \\
\hline Acer & Acer negundo L. & Aceraceae & 0,26 & 3,66 \\
\hline Ipê amarelo & $\begin{array}{l}\text { Tabebuia alba (Cham.) } \\
\text { Sandw. }\end{array}$ & Bignoniaceae & 0,12 & 3,33 \\
\hline Pau-Ferro & $\begin{array}{c}\text { Caesalpinea ferrea Mart. ex } \\
\text { Tul }\end{array}$ & Fabaceae & 0,29 & 3,26 \\
\hline Hibiscus & Hibiscus rosa-sinensis L. & Malvaceae & 0,17 & 2,66 \\
\hline Sibipiruna & $\begin{array}{l}\text { Caesalpinia peltophoroides } \\
\text { Benth. }\end{array}$ & Fabaceae & 0,28 & 1,86 \\
\hline Jerivá & $\begin{array}{l}\text { Syagrus romanzoffiana } \\
\text { (Cham.) Glassman }\end{array}$ & Arecaceae & 0,29 & 1,53 \\
\hline $\begin{array}{l}\text { Cerejeira-do- } \\
\text { Japão }\end{array}$ & Prunus serrulata Lind L. & Rosaceae & 0,11 & 1,46 \\
\hline $\begin{array}{l}\text { Jacarandá- } \\
\text { mimoso }\end{array}$ & $\begin{array}{c}\text { Jacaranda mimosifolia D. } \\
\text { Don. }\end{array}$ & Bignoniaceae & 0,34 & 1,40 \\
\hline Monjoleiro & $\begin{array}{c}\text { Anadenanthera colubrina } \\
\text { (Vell.) Brenan }\end{array}$ & Fabaceae & 0,58 & 1,07 \\
\hline Pitanga & Eugenia uniflora L. & Myrtaceae & 0,05 & 0,93 \\
\hline Magnólia & Magnolia grandiflora Linné & Magnoliaceae & 0,48 & 0,93 \\
\hline $\begin{array}{c}\text { Cassia } \\
\text { manduirana }\end{array}$ & $\begin{array}{l}\text { Senna macranthera (Collad.) } \\
\text { Irwin \& Barn. }\end{array}$ & Fabaceae & 0,17 & 0,80 \\
\hline Canafístula & $\begin{array}{l}\text { Peltophorum dubium } \\
\text { (Spreng.) Taub. }\end{array}$ & Fabaceae & 0,35 & 0,80 \\
\hline
\end{tabular}


A partir das informações de identificação da Tabela 01, definiram-se as espécies que apresentam maiores problemas com relação às variáveis analisadas para acessibilidade.

No levantamento realizado, 5,14\% das árvores do centro de Curitiba apresentaram tortuosidade. Para esse aspecto a espécie de maior freqüência foi $H$. rosa-sinensis, em que $37,5 \%$ dos seus indivíduos apresentaram tortuosidade, seguido do J. mimosifolia, $S$. macranthera e E. uniflora visto na Figura 02. Por outro lado, as espécies como $C$. peltophoroides, $P$. dubium, S. romanzoffiana, T. alba e L. pacari não apresentaram tortuosidade em nenhum de seus indivíduos na área analisada.

Para a acessibilidade numa rua arborizada, a tortuosidade das árvores é um dos fatores de impedimento do fluxo de pedestre nas calçadas, pois, o ideal é que as árvores de rua tenham fuste reto para melhor facilitar o tráfego de pedestres. Gonçalves et al. (2004) afirma que mudas ideais para a arborização urbana deverão apresentar entre outras características, tronco retilíneo.

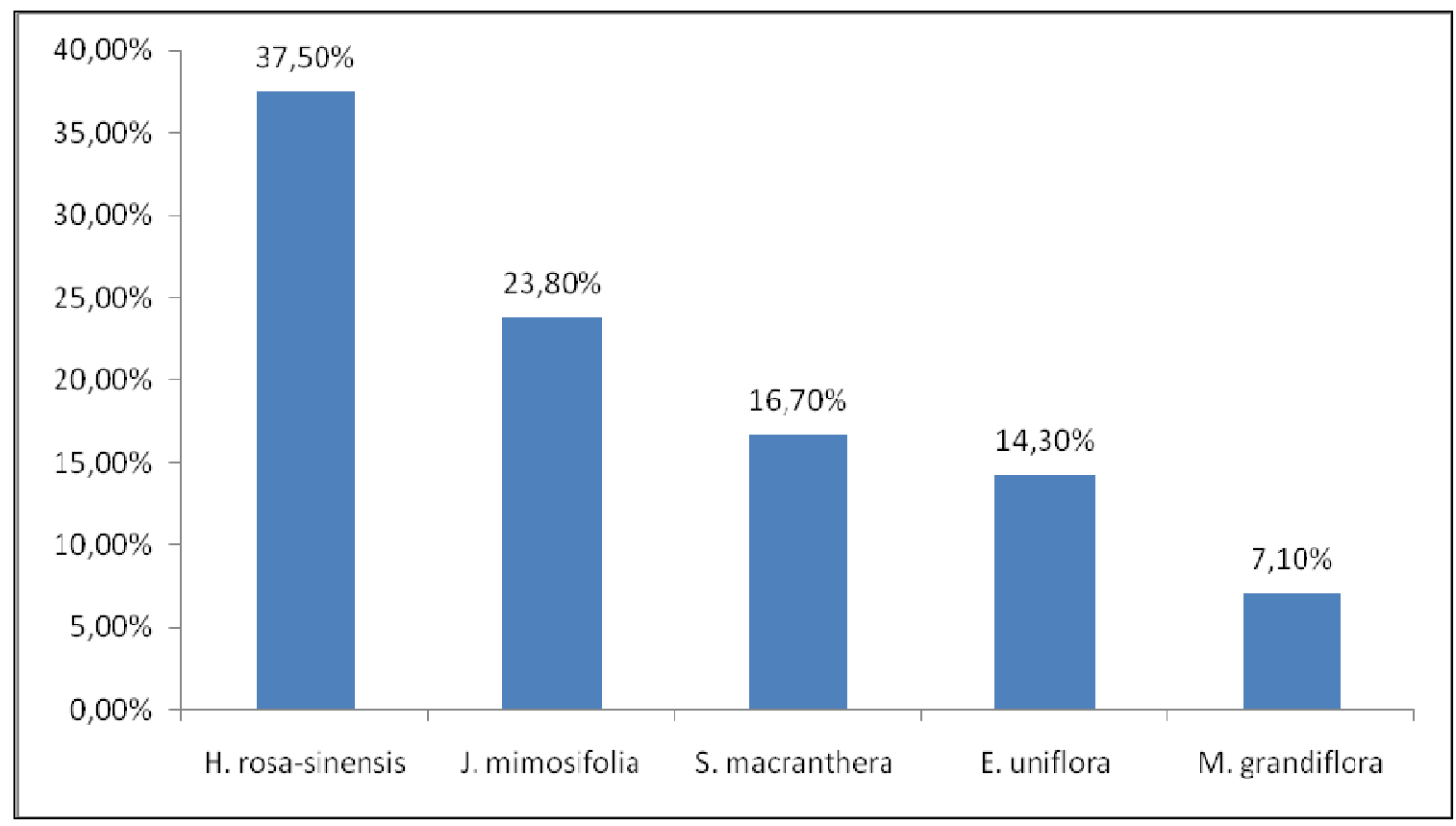

FIGURA 2. Percentual de tortuosidade das espécies mais freqüentes no Centro de Curitiba/PR.

FIGURE 2. Percentage of tortuosity of the most common species in Curitiba's downtown neighborhood.

A falta da conformidade no fuste (tortuosidade) pode ser proveniente da falta de manejo, problemas na condução e tutoramento da planta em estágio de muda, ou ainda, a proximidade das construções às árvores. A tortuosidade pode tanto afetar o acesso aos pedestres como também para os veículos, como pode ser observado na figura 3 . O caso da acentuada tortuosidade do Hibisco também está associado à estrutura do caule que possui 
bastante flexibilidade. Além disso, a referida espécie é inapropriada para as ruas porque não é uma espécie arbórea e sim arbustiva.

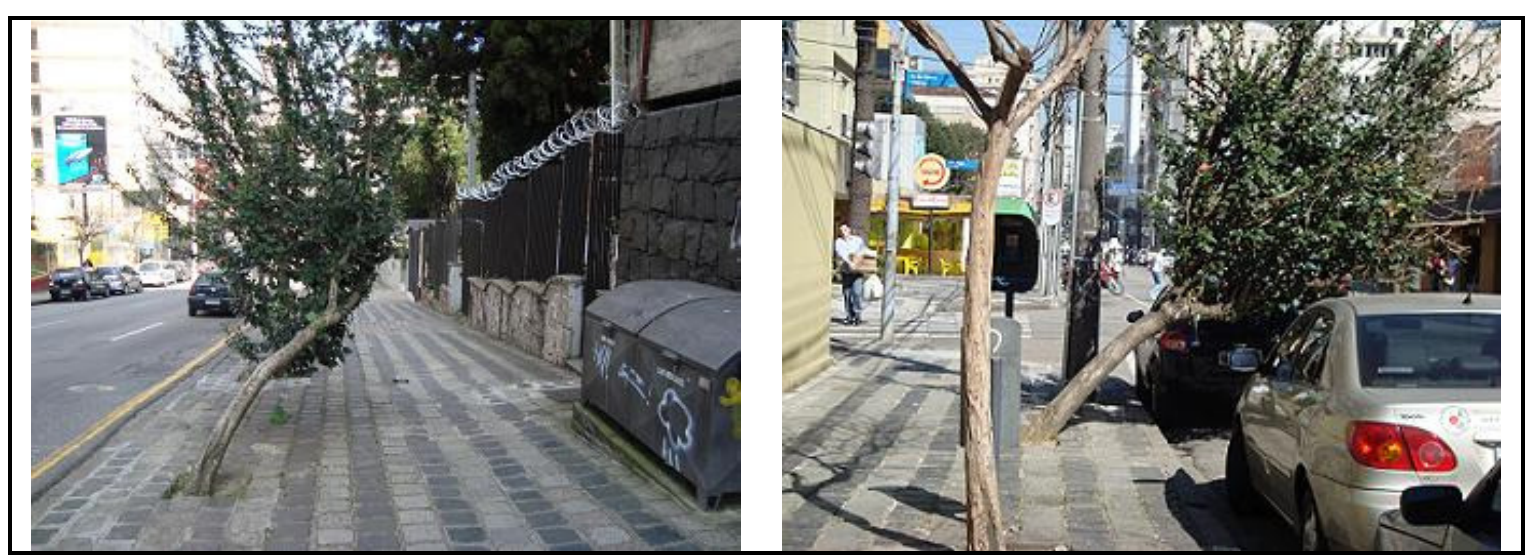

Fonte: fotografado pelos autores, outubro de 2009.

FIGURA 3. Exemplos de tortuosidade em Hibiscus rosa-sinensis L. nas calçadas do Centro de Curitiba-PR.

FIGURE 3. Examples of tortuosity on Hibiscus rosa-sinensis L. in the sidewalks of Curitiba's downtown.

Das árvores levantadas, 18,8\% apresentaram uma altura de bifurcação abaixo de $1,80 \mathrm{~m}$. A altura de bifurcação também conhecida pelo ponto de inversão morfológica representa um problema com relação à permissividade ao trânsito livre entre os pedestres, principalmente aqueles de mobilidade reduzida. De acordo com Biondi e Althaus (2005) para que a árvore tenha maior adequação nas calçadas, sem transtornos com os pedestres, é necessário que tenha o tronco livre de ramificações até a altura de $1,80 \mathrm{~m}$. 


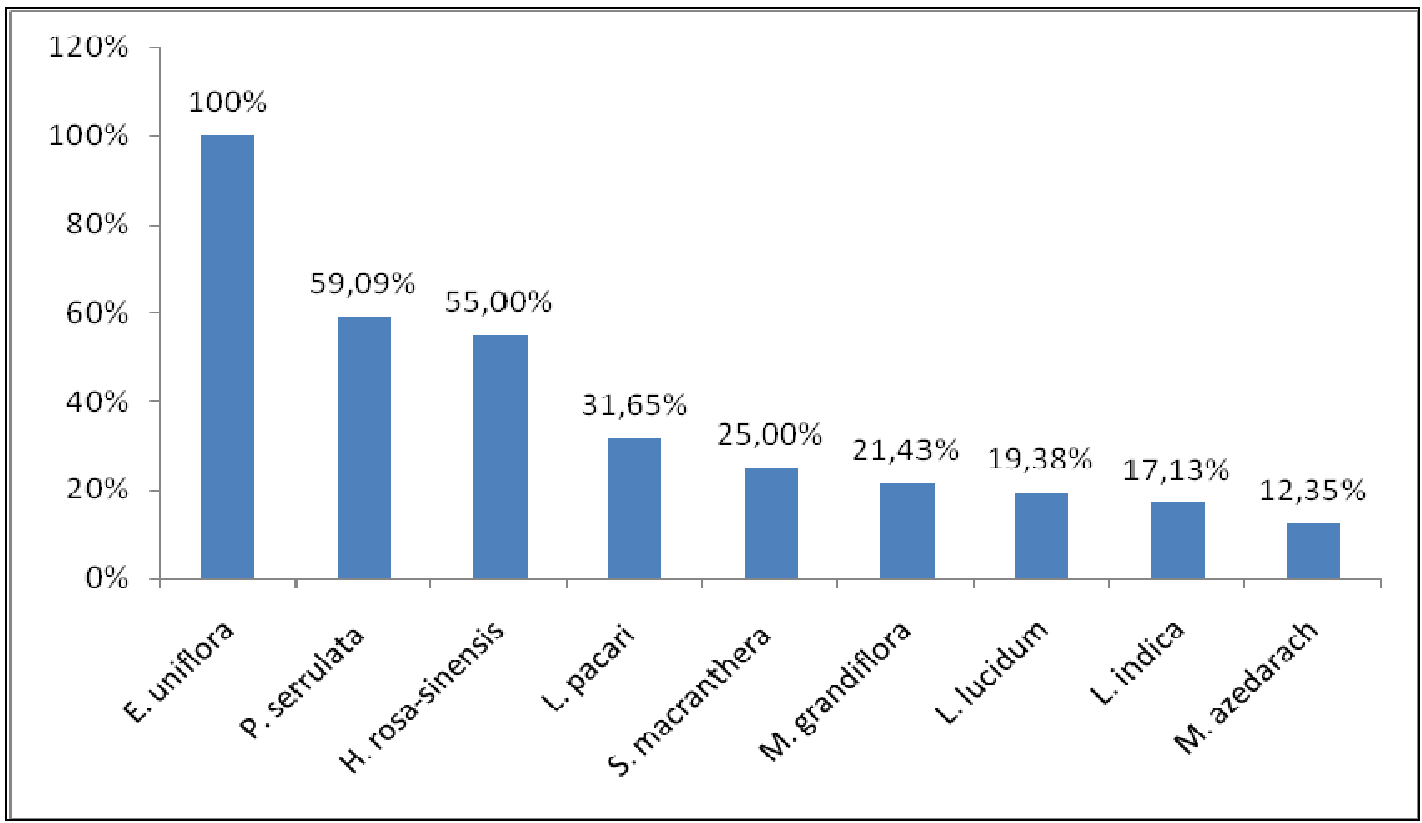

FIGURA 4. Freqüência da altura de bifurcação por espécies encontradas na arborização viária do centro de Curitiba-PR.

FIGURE 4. Frequency of fork height of the tree species found in the streets of Curitiba's downtown.

$\mathrm{Na}$ figura 04, pode-se verificar que os indivíduos da espécie $E$. uniflora tiveram sua totalidade fora do padrão estabelecido. Assim como a Prunus serrulata, H. rosa-sinensis, $L$. pacari e Senna macranthera, representaram maiores freqüências indesejáveis para altura de bifurcação. No entanto, espécies como $S$. romanzoffiana, $A$. colubrina e $C$. ferrea não apresentaram problema para esta variável.

Para que seja efetivo o planejamento da arborização nas ruas deve-se evitar o plantio de mudas com altura de bifurcação abaixo de 1,80 m., a fim de evitar futuros transtornos aos transeuntes com as árvores adultas.

A destruição de calçadas por interferência das raízes faz parte do elenco de problemas que dificultam a acessibilidade nos centros urbanos. A figura 5 mostra exemplos referentes à condição de raízes que foram avaliadas sob três categorias, sendo: R1 - raízes superficiais no passeio (Figura 5A e 5B); R2 - raízes superficiais no canteiro (Figura 5C) e R3 - raízes subterrâneas (Figura 5D). 

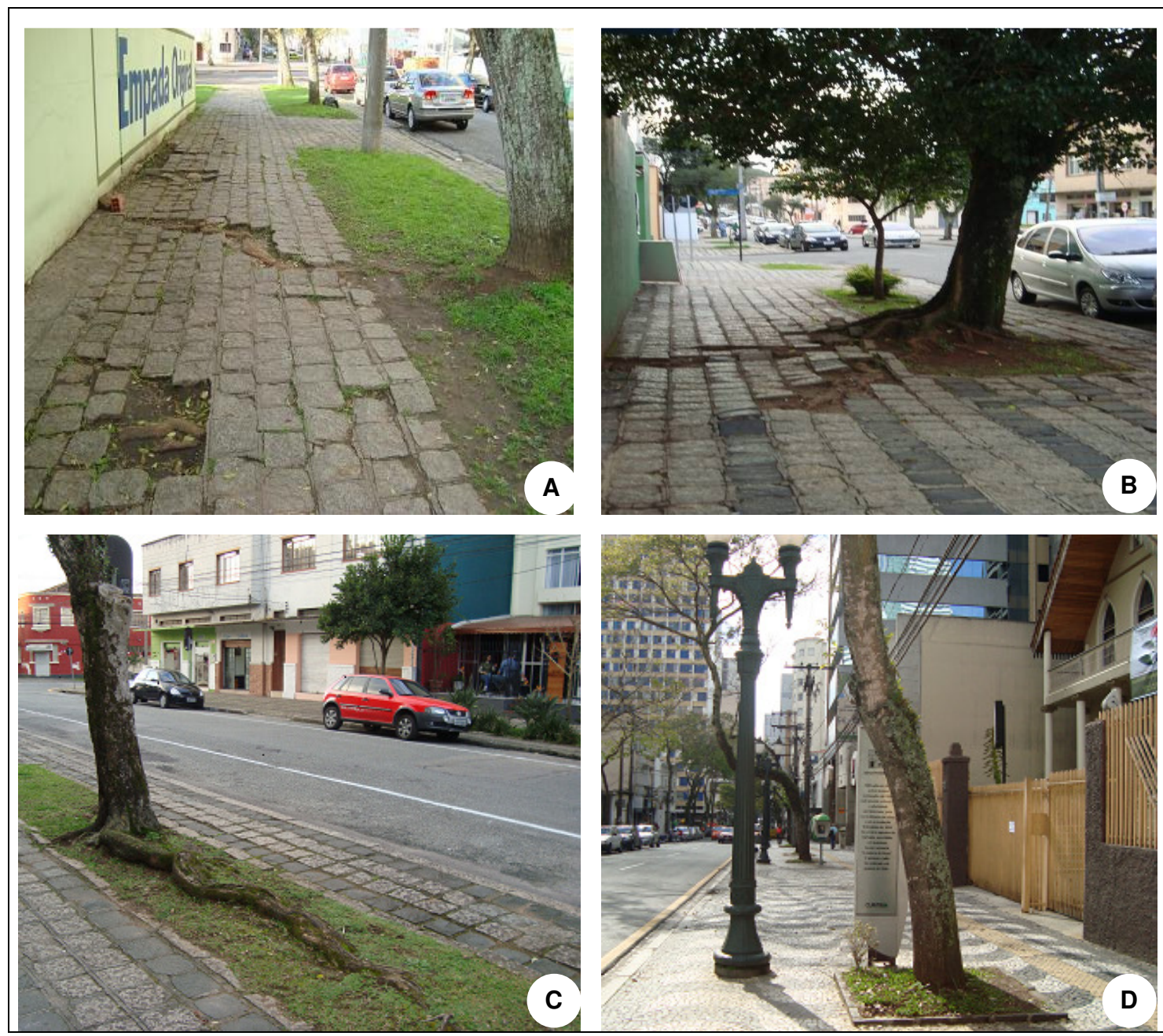

Fonte: fotografado pelos autores, outubro de 2009.

FIGURA 5. Exemplos do desenvolvimento de raiz na arborização de ruas no centro de Curitiba-PR. A e B: Raízes do tipo R1. C: Raiz do tipo R2. D: Raiz do tipo R3.

FIGURE 5. Examples of root development in the streets tree planting in Curitiba's downtown A and B: Roots type R1. C: Root type R2. D: Root type R3.

De acordo com CREA-PR (2008) a área de faixa livre é destinada exclusivamente à circulação de pedestres, portanto deve estar livre de quaisquer desníveis, obstáculos físicos, temporários ou permanentes ou vegetação.

Segundo Biondi e Althaus (2005) o ideal para as calçadas é o uso de espécie com raiz pivotante para evitar rachaduras nas calçadas e construções. Desse modo, as raízes que não impedem a fluência do trânsito de pedestres são consideradas as do tipo R1 e R2.

Nota-se que as espécies que apresentaram maior percentual de raízes com o Tipo $\mathrm{R} 1$ relativos ao afloramento de raízes no passeio foram: $A$. colubrina, M. grandiflora, T. tipu, L. Iucidum e T. heptaphylla, de acordo com a figura 6 .

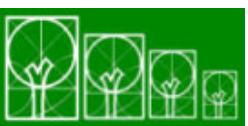

$\mathbf{S} \cdot \mathbf{B} \cdot \mathbf{A} \cdot \mathbf{U}$ Soc. Bras. de Arborização Urbana 


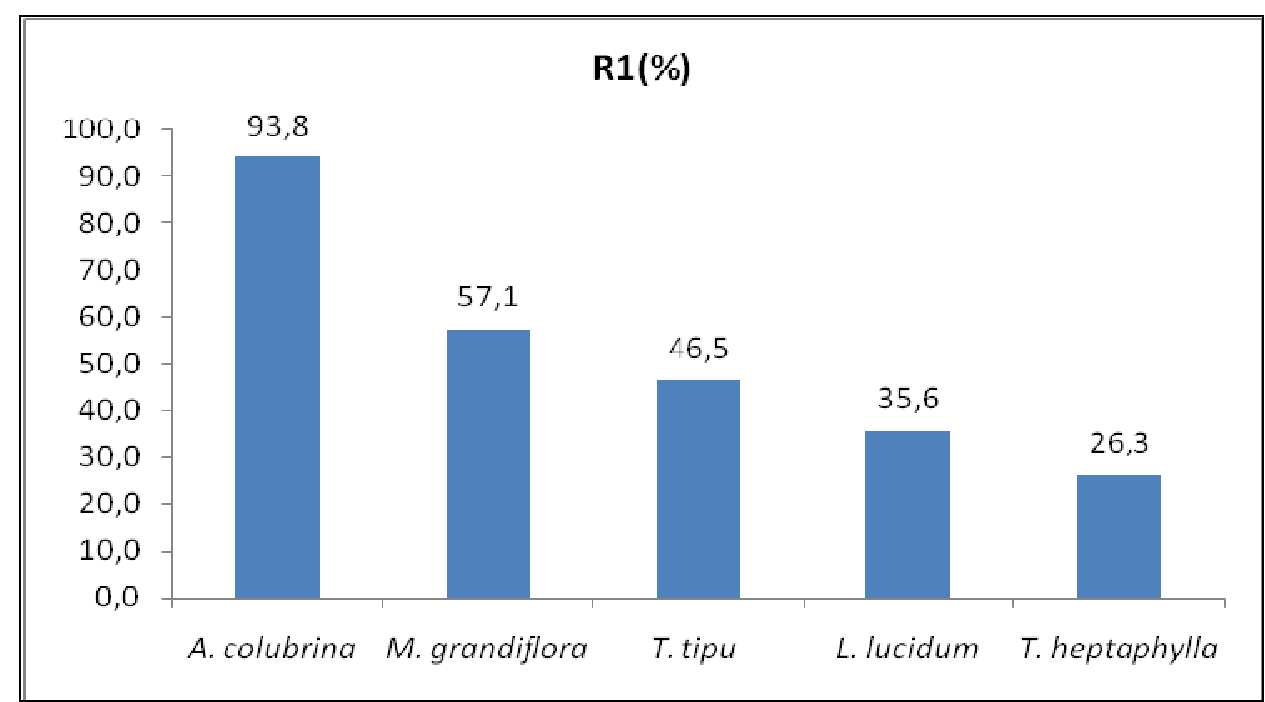

FIGURA 6. Espécies que apresentam maior freqüência da condição de raiz do tipo R1 (raízes superficiais no passeio) no centro de Curitiba - PR.

FIGURE 6. Species that have a higher frequency of root type R1 (surface roots on the sidewalk) at Curitiba's downtown.

Biondi e Althaus (2005) ressaltam que as áreas de canteiro são geralmente pequenas para o desenvolvimento das árvores de rua, e são alteradas constantemente pelo alargamento de rua ou reparo de linha subterrânea.

As espécies classificadas como R2 (Figura 5C) podem apresentar raízes superficiais e não configurar problemas para acessibilidade, pois, a área do canteiro permite o desenvolvimento radicular.

O percentual das espécies que apresentaram raízes subterrâneas, ou seja, que indicaram condições adequadas do sistema radicular segundo a literatura são mostrados na figura 07. 


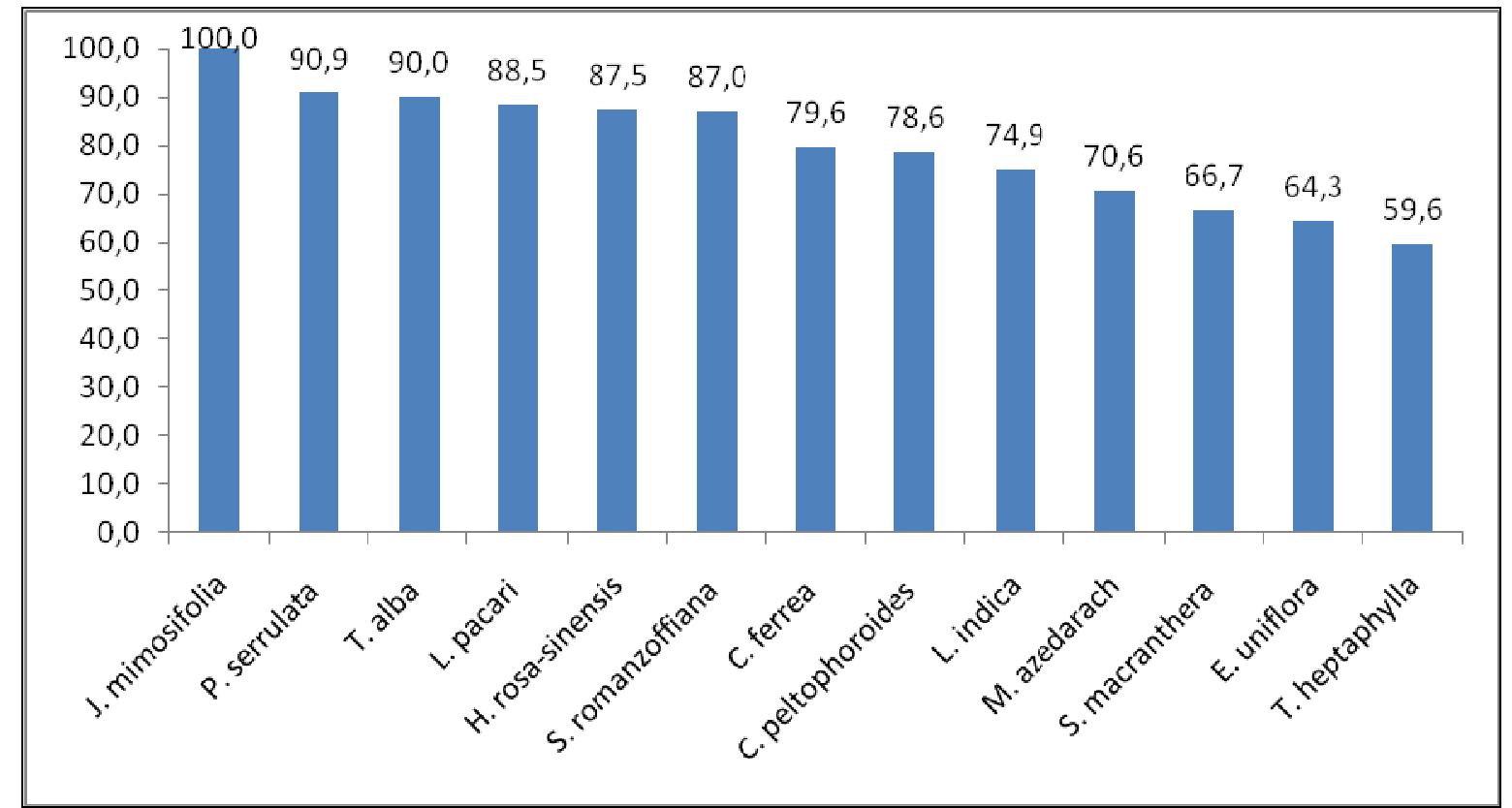

FIGURA 7. Espécies que apresentaram mais de $50 \%$ de raiz do tipo R3 (raízes subterrâneas), na arborização de ruas do centro de Curitiba - PR.

FIGURE 7. Tree species that had more than $50 \%$ of root type R3 (underground roots) in the streets of Curitiba's downtown.

J. mimosifolia obteve $100 \%$ dos seus indivíduos sem raízes superficiais, minimizando problemas em relação à acessibilidade. P. serrulata e T. alba, apresentaram cerca de $90 \%$ de cada um dos seus indivíduos sem problemas com raízes.

Os problemas advindos do afloramento das raízes nas calçadas podem ser devido ao solo urbano, produto das ações antrópicas, consequentemente compactado restringe o crescimento adequado das raízes. Outro motivo seria o comportamento das espécies no meio urbano (alteração da profundidade do lençol freático e da profundidade do solo), condições adversas ao ambiente de ocorrência natural da espécie.

As calçadas centrais de acordo com a norma vigente devem ser divididas em: largura do canteiro, largura da construção ao passeio e largura do meio-fio ao canteiro.

Para CREA-PR (2008) as áreas de faixa livre devem possuir largura mínima de $1,20 \mathrm{~m}$ (um metro e vinte centímetros). Na área analisada foram encontrados percentuais demonstrando que as larguras das construções ao canteiro representam $95,25 \%$ dos indivíduos que atendem o exigido para acessibilidade, sendo que deste percentual, 15,3\% estão com problema de raiz superficial. Aproximadamente $20 \%$ das áreas de faixa livre do centro da cidade apresentam interferência das variáveis de raiz superficial e tortuosidade.

Já a largura do meio-fio ao canteiro $75,08 \%$ não atendem a largura de 1,20m, sendo considerada faixa de serviço de acordo com o CREA-PR (2008), que é destinada à 
colocação de árvores, rampas de acesso para veículos ou portadores de deficiências, poste de iluminação, sinalização de trânsito e mobiliário urbano como bancos, floreiras, telefones, caixa de correio e lixeiras.

Não há como analisar a arborização de ruas e acessibilidade sem discorrer dos tipos de calçadas predominantes, segundo CREA-PR (2008), a estrutura deve possuir superfície regular, firme, contínua e antiderrapante sob qualquer condição, além de ser contínua, sem qualquer emenda, reparo ou fissura.

No estudo em questão, a predominância dos tipos de calçada circundando cada árvore foi paralelepípedo $(70,33 \%)$ e o petit pavet $(24,8 \%)$, apresentando estrutura física diferente da literatura. Cerca de $3,7 \%$ do calçamento presente para cada árvore analisada apresentaram composição mista, ou seja, mais de um tipo de pavimentação, exemplo muito comum é petit pavet com Tipo A.

As estruturas estabelecidas pelo CREA-PR (2008) para construção de calçadas, com piso antiderrapante, disposto com mínimos espaçamentos entre as estruturas de revestimento, ainda não estão implantadas no Centro da cidade e suas porcentagens são menores que $1 \%$, considerados os tipos $\mathrm{A}$, B e C descritos na metodologia.

\section{CONCLUSÃO}

A acessibilidade nas calçadas foi interferida tanto pelo sistema radicial das árvores quanto ao revestimento dos passeios nas calçadas.

A espécie L. lucidum foi a mais freqüente na área central, apresentando maior freqüência de conflito do sistema radicular com o trânsito de pedestres nas calçadas. $H$. rosa-sinensis apresentou alto percentual de altura de bifurcação negativa e tortuosidade, fatores relativos a produção de mudas e manutenção da arborização de ruas.

O tamanho das calçadas, largura de passeio e de canteiro não interferiu na acessibilidade na região central da cidade de Curitiba. Já o revestimento dos passeios foi a variável que mais interferiu na acessibilidade, por não haver um uma predominância do padrão sugerido pelo CREA no município, tais como: superfície regular, firme, contínua e antiderrapante sob qualquer condição, além de ser contínua, sem qualquer emenda, reparo ou fissura.

Recomenda-se o desenvolvimento de pesquisas sobre a relação da arborização urbana com a acessibilidade dos transeuntes, visto que maior parte da literatura encontrada

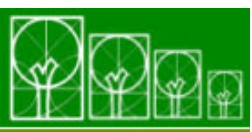

$\mathbf{S} \cdot \mathbf{B} \cdot \mathbf{A} \cdot \mathbf{U}$ Soc. Bras. de Arborização Urbana 
está voltada para construção civil, que em geral relega a planos inferiores a presença de árvores na cidade.

\section{REFERÊNCIAS}

BIONDI, D.; E ALTHAUS. M. Árvores de Rua de Curitiba: cultivo e manejo. Curitiba: FUPEF, 2005.

BRASIL ACESSÍVEL. Implementação de Políticas Municipais de Acessibilidade. Caderno 4, 2005. Disponível em: http://www.cidades.gov.br/secretarias-nacionais/transportee-mobilidade/arquivos/Brasil\%20Acessivel\%20-\%20Caderno\%204.pdf. Acesso em: 02 de setembro de 2010.

CREA-PR. Acessibilidade: Responsabilidade Profissional. Cadernos do CREA-PR. № 4. 2 $2^{\mathrm{a}}$ Ed, 2008.

CREA-PR. Disponível em: http://www.crea-pr.org.br/crea2/html/assessoria co municacao/acessibilidade/. Acesso: 18 de julho de 2009.

GONÇALVES, E.O. et al. Avaliação Qualitativa de Mudas Destinadas à Arborização Urbana no estado de Minas Gerais. Revista Árvore, Viçosa-MG, v.28, n.4, p.479- 4862004.

GUARAPARI, Prefeitura Municipal. Calçada Cidadã: Normas para Construção, Reforma e Conservação de Calçadas, 2009.

GUIA DOS DIREITOS DAS PESSOAS COM DEFICIÊNCIA. 2 ${ }^{\mathrm{a}}$ edição, revisada e atualizada, São Paulo, 2007. Disponível em: http://www.parkinson.org.br/imagens/guia/guia direito.pdf. Acesso em dezembro de 2009.

INSTITUTO BRASILEIRO DE GEOGRAFIA E ESTATÍSTICA - IBGE. Censo 2000. Disponível em: http://www.ibge.gov.br/censol. Acesso em novembro de 2009.

IPPUC - Instituto de Pesquisa e Planejamento Urbano de Curitiba. Mapa do bairro centro. Curitiba: IPPUC, jun. 2005. Disponível em: http://www.ippuc.org.br/informando/index mapasarruamento.htm. Acesso em 25 de junho de 2009.

LONDRINA, Prefeitura Municipal. Calçada para Todos. Novembro. 2004.

MAACK, R. Geografia Física do estado do Paraná. Ed. J. Olympio, Curitiba: Secretaria da Cultura e do Esporte do Governo do estado do Paraná, 1981. 450p.

PEREIRA, R. I. Arte, paisagem e arborização urbana. Trecho da tese de doutorado "O SENTIDO DA PAISAGEM E A PAISAGEM CONSENTIDA: projetos participativos na produção de espaço livre público" - FAU/USP, 2006.

PREFEITUA MUNICIPAL DE CURITIBA - PMC. Perfil de Curitiba. Disponível em: http://www.curitiba.pr.gov.br/publico/cidade.aspx?idf=145\&servico=39. Acesso em: 10 de março de 2010. 
RODERJAN, C. V.; GALVÃO, F.; KUNIYOSHI, Y. S.; HATSCHBACH, G. G. As regiões fitogeográficas do Estado do Paraná. Revista Ciência e Ambiente, 24, jan/jun 2002. 7592p.

SÃO PAULO, Prefeitura Municipal. Conheça as Regras para Arrumar a sua Calçada. Programa Passeio Livre, Novembro, 2005.

VITÓRIA, Prefeitura Municipal. Projeto Calçada Cidadã. Dezembro, 2002. 